\title{
DOC INTERCALIBRATION TO END SOON
}

\author{
By Jonathan $\mathrm{H}$. Sharp
}

\begin{abstract}
A
N INTERNATIONAL INSTRUMENT and methods comparison for the measurement of Dissolved Organic Carbon (DOC) in seawater has been underway since 1993. The intent of this effort is to develop coherence between laboratories on DOC measurements so that accurate global and long-term analyses of DOC data can be made and so information based on accurate DOC measurements will be consistent with other oceanographic information. Although the orientation of the intercalibration is oceanographic and especially relates to the Joint Global Ocean Flux Study, a number of aquatic analysts working in freshwater systems are also involved.
\end{abstract}

I am carrying out this NSF-funded effort with guidance from a steering committee consisting of John Hedges (University of Washington) Cindy Lee (State University of New York at Stony Brook), Charles Hopkinson (Marine Biological Laboratory, Woods Hole), and Anthony Knap (Bermuda Biological Station). The DOC intercalibration is an outgrowth of the Seattle workshop held in 1991 (Hedges and Lee, 1993). Results of our early instrument comparisons have been published (Sharp et al. 1993, 1995; Sharp, 1993).

The broad community instrument and methods comparison has been carried out in a two-stage format. In the first stage, analysts were sent a few samples with known concentrations to check performance of their analyses before the unknown samples were sent. Approximately 50 analysts returned results in the first stage. In the second stage, there are 13 samples that include a "blank" and two standards of undisclosed DOC content plus 10 unknown natural samples. To date,

Jonathan H. Sharp, Graduate College of Marine Studies, University of Delaware, Lewes, DE 19958 USA. e-mail: jsharp@udel.edu.
68 sets of samples have been sent out and results have been received from 45 of the analysts. By simply examining the blank and standards, a screening procedure is being used before more thoroughly examining the results for the 10 unknowns. Based on the screening procedure, several analysts have taken the opportunity to run a second set of samples; to date 32 analysts have returned results for the standards that are within the $10 \%$ error predetermined as the screening criterion.

The majority of the analysts involved are using high temperature combustion (HTC) instruments; 11 are using wet chemical oxidation (WCO) methods. HTC instruments being used include those made by Shimadzu, Ionics, Dohrmann, Dimatoc, Carlo Erba, Sumika, Sklar, Columetrics, and several homemade designs. WCO methods being employed all use persulfate and/or UV radiation. Instruments include those made by Dohrmann, OI, Technicon, and homemade methods. Analysts involved are working in laboratories in the United States, France, the Canary Islands, Norway, Canada, Belgium, Germany, Bermuda, Taiwan, Japan, India, Sweden, the Netherlands, Ireland, Denmark, the United Kingdom, Australia, and Turkey.

Many of those individuals who are active in accurate DOC analyses and who have published DOC data recently are involved in this intercalibration but not all of them. Efforts are being made now to include those who have not yet participated. Because of the large number of individuals involved, this exercise will work well to verify whether or not one can obtain credible DOC values.

Anyone who has received samples and not yet sent in results is requested to complete analyses and send results as soon as possible. Anyone who has not received samples and who wishes to participate, please contact me at the mail or email address given below (please indicate your full address including street number so that UPS shipment can be made). Samples will be sent and results received for only a few more months (until March 1996). The large number of participants to date indicates concern and interest in accurate DOC analytical capability. Results to date indicate great success in multiple laboratories being able to obtain similar results. The more thorough analyses, to be carried out in the near future, of already submitted and future data will indicate just how similar the results are.

\section{References}

Hedges, J.I. and C. Lee, (eds.) 1993: Measurement of dissolved organic carbon and nitrogen in natural waters. Mar. Chem., 41 (1-3), 290 pp.

Sharp, J.H., 1993: The dissolved organic carbon controversy: an update. Oceanography, 6, 45-50.

, R. Benner, L. Bennett, C.A. Carlson, R. Dow and S.E. Fitzwater, 1993: Re-evaluation of high temperature combustion and chemical oxidation measurements of dissolved organic carbon in seawater. Limnol. Oceanography, 38, 1774-1782.

, R. Benner, L. Bennett. C.A. Carlson, S.E. Fitzwater, E.T. Peltzer and L.M. Tupas, 1995: Analyses of dissolved organic carbon in seawater: the JGOFS EqPac methods comparison. Mar. Chem., 48, 91-108. 